\title{
50th Anniversary Dinner
}

A celebratory dinner was held in the Crypts of London's Guildhall on Monday, 28 September 1997. Professor David Hamblen, Chairman of the Council of Management, welcomed the American editor, Dr Henry R. Cowell, a number of other distinguished guests and present and past members of the Editorial Board. The speakers included Dr Cowell, who presented a commemorative plaque on behalf of the
American volume of the Journal, and Sir Rodney Sweetnam, past Chairman of the Council of Management and current President of the Royal College of Surgeons of England.

A special welcome was given to Lady Watson-Jones, widow of Sir Reginald Watson-Jones, the founder and first Editor of the British volume.


Sir Rodney Sweetnam and Mr David L. Evans, ex-Chairmen of the Council of Management; Professor David Hamblen; and Dr Henry R. Cowell presenting the plaque.
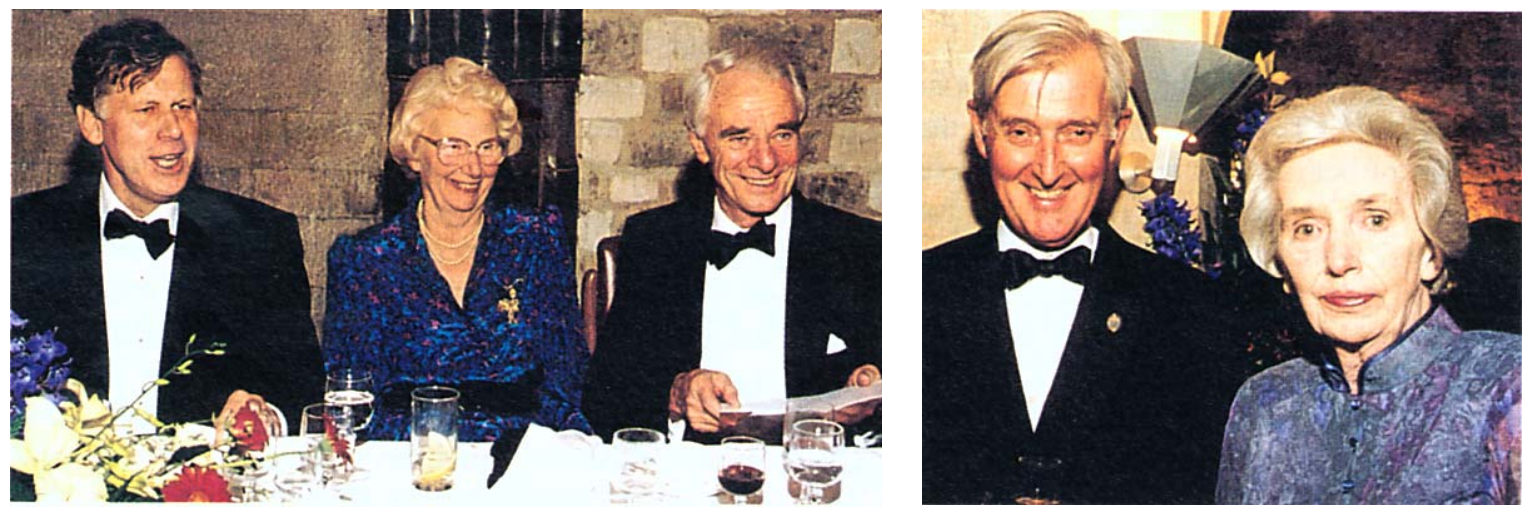

Mr Michael Benson, a member of Council with Mrs Betts Evans and Mr Philip Fulford, the current Editor; Mr Anthony Catterall, a member of Council, with Lady Watson-Jones.



Mr Frank Horan, Deputy Editor, with Professor Jacques Duparc, Editorial Secretary of EFORT, and Madame Duparc. 

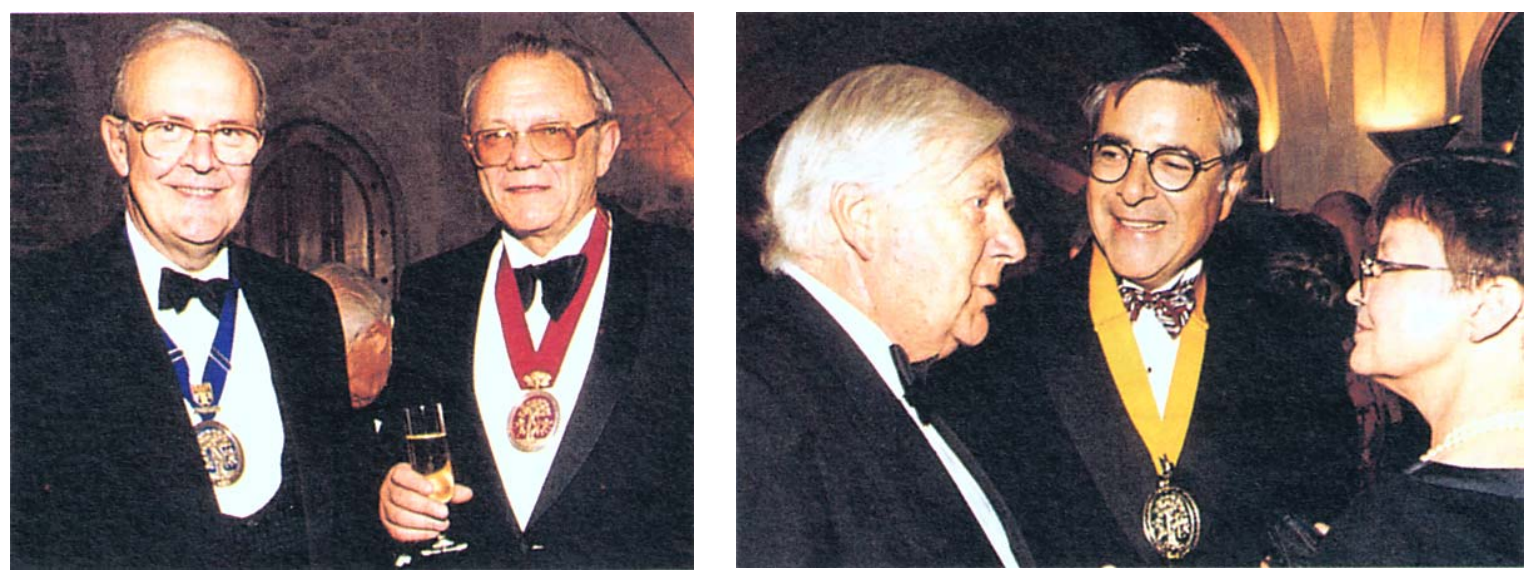

Mr Paddy Mulligan, President of the British Orthopaedic Association with Professor Robert Snowdowne, President of the South African Orthopaedic Association: Mr John Goodfellow, Editor Emeritus, with Professor Norman Schachar, a member of the Editorial Board representing the President of the Canadian Orthopaedic Association, and Mrs Schachar.
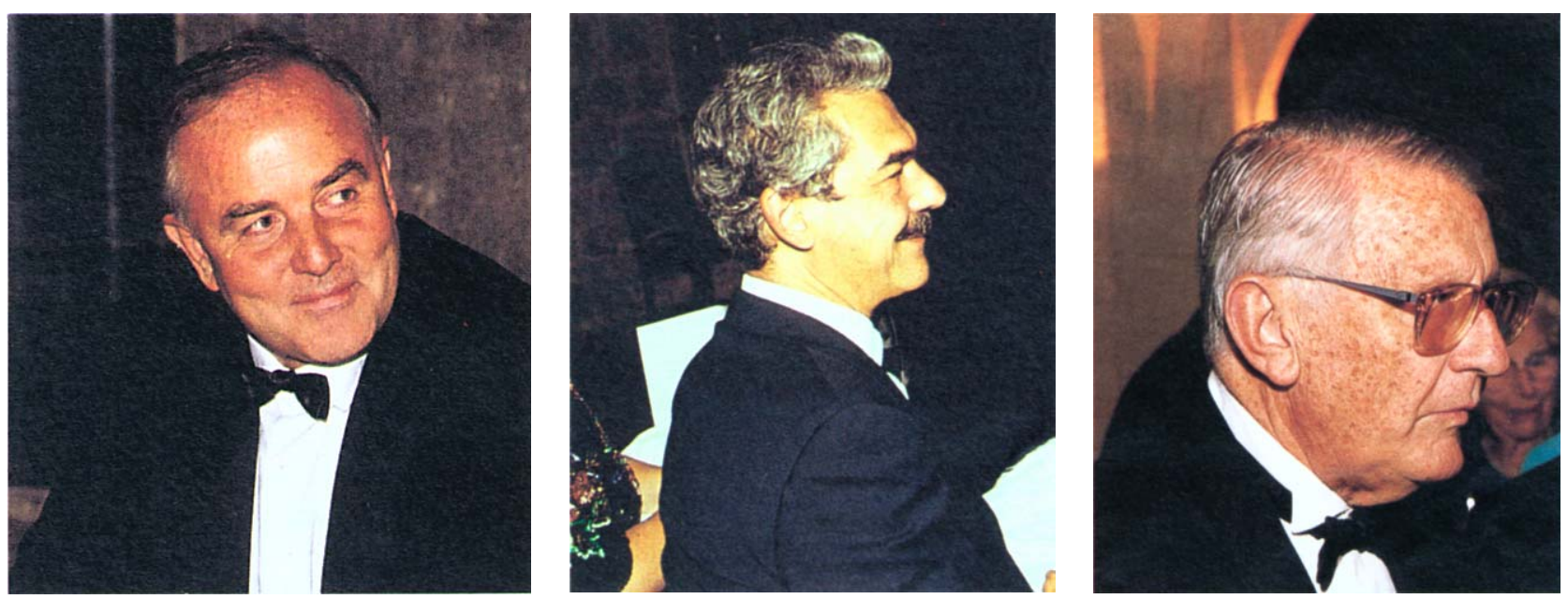

Professor Lars Lidgren, a member of the Editorial Board and President of the European Orthopaedic Research Society; Professor Franco Postacchini, a member of the Editorial Board; and Dr Raphael Miguel De Esteve, a member of the Research Board.



Mrs Jean Fulford and Mr Derick St Clair Strange, author of a book on the ABC Travelling Fellows soon to be published by the Journal.

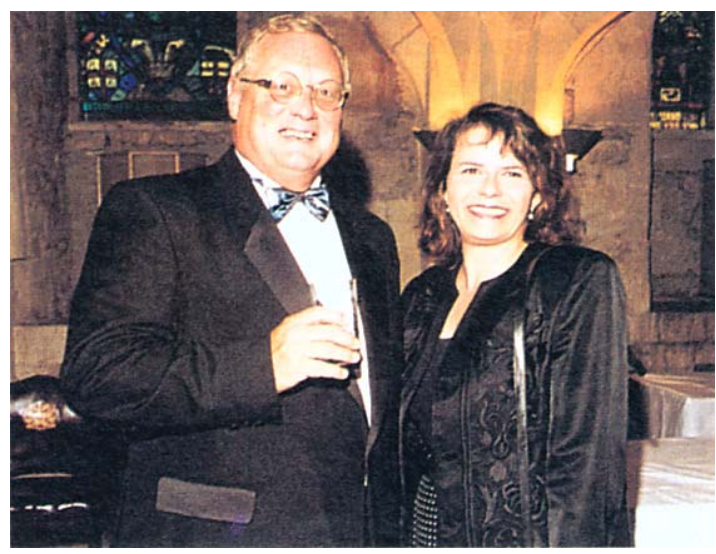

Mr Mike Andrew, Group Operations Director of Martin's Printing Group, and Ms Fay Miller, Production Manager of the Journal. 